\title{
Prognostic Role of Antibody Reactivity to Melanoma
}

\author{
Daniel R. Vlock, Rebecca DerSimonian, and John M. Kirkwood \\ Departments of Medicine, Dermatology, Epidemiology, and Public Health, \\ Yale University School of Medicine, New Haven, Connecticut 06510
}

\begin{abstract}
Antibody reactivity against cultured allogeneic melanoma Y-Mel 81:180 was studied in 43 patients who participated in an adjuvant trial for stage I and II melanoma. Serum samples were obtained at trial entry within 2 mo of definitive surgery. At the time of serum acquisition, all patients were free of disease by physical examination and routine radiologic and laboratory parameters. Serum antibody reactivity was tested for by protein $A$ hemadsorption before and after acid dissociation and ultrafiltration of serum. We have previously shown that this technique for immune complex dissociation augments autologous antibody reactivity. Results of serum antibody reactivity were scored by an investigator blinded to the patient's clinical status. Of the 43 patients studied, 15 relapsed and 28 remained disease-free. At study entry, there were 25 stage I patients and 18 stage II patients. Breslow depth was $3.25 \pm 2.5 \mathrm{~mm}$ in relapse patients and $1.67 \pm 1.1 \mathrm{~mm}$ in disease-free patients. The presence and titer of antibody directed against melanoma in either native serum or serum dissociated from immune complexes was found to be associated with eventual relapse $(P=0.0001)$. When results were subgrouped by stage of disease, Breslow depth, and hypopigmentation, antibody reactivity was still correlated with eventual relapse. The incidence and titer of antibody reactivity against melanoma appears to be a new prognostic factor in predicting eventual disease recurrence.
\end{abstract}

\section{Introduction}

A basic premise of tumor immunology is that neoplastic cells are distinguished from their normal counterparts by the presence of tumor-restricted antigens (1). Melanoma is a tumor in which immune factors have been implicated in the pathogenesis and natural history of the disease. Melanoma cell surface antigens of several degrees of restriction have been detected by antibody of autologous, allogeneic, and xenogeneic origin (2-10). Several of these melanoma cell surface antigens, which have been shown to be shared or common, have been detected upon a majority of melanomas studied. The relationship of these antigens to the immunobiology of cancer is uncertain. However, it has been suggested that the presence of certain cell surface antigens or the existence of antibody to other such antigens is of prognostic significance $(11,12)$.

Address reprint requests to Dr. Vlock, University of Pittsburgh School of Medicine, Division of Hematology-Oncology, 922 Scaife Hall, Pittsburgh, PA 15261.

Received for publication 14 June 1985 and in revised form 12 December 1985.

J. Clin. Invest.

(C) The American Society for Clinical Investigation, Inc.

0021-9738/86/04/1116/06 $\$ 1.00$

Volume 77, April 1986, 1116-1121
It has been reported that antibody which is reactive to autologous tumor is infrequent and of low titer in patients with metastatic melanoma $(7,9,13)$. In those patients, we have demonstrated that antigen-antibody complexes may serve as a reservoir from which antibody binding to autologous tumor may frequently be retrieved (13). We have also shown in the serum of patients with metastatic disease that antibody reactivity, which is followed serially at frequent intervals, may be correlated with tumor progression and clinical course (14).

These findings suggest that host-derived antibody responses to cancer detect physiologically relevant antigens which may be related to the clinical course and prognosis of malignancy. We have now turned to an examination of the serum of patients without active metastatic disease to determine the relationship of melanoma-reactive antibody to clinical course. We elected to study the allogeneic antibody response in $\mathbf{4 3}$ patients with stage I and II melanoma prospectively entered into an adjuvant protocol.

\section{Methods}

\section{Patient population}

106 patients with high risk stage I or stage II (lymph node metastases) melanoma were entered into an adjuvant study. Following definitive surgery, all patients were randomized to receive 5-methyl-(3,3-dimethyl1-triazeno)-imidazole-4-carboxamide (DTIC) ${ }^{1}$ plus bacillus CalmetteGuerin (BCG), depigmentation therapy with monobenzyl ether of hydroquinone (MBEH), or null (standard) therapy. Patients were followed for relapse by physical, laboratory (complete blood count and liver function tests), and radiological (chest $x$-ray, liver-spleen scan, tomographic ${ }^{67} \mathrm{Ga}$ scan) examination at 3-, 4-, or 6-mo intervals in the first, second, and third yr after diagnosis. The results of this trial have been reported elsewhere (15). No statistically significant difference in relapse rate or death was noted among the three study groups.

\section{Serological methods}

Serum samples were available in 43 of the 106 patients entered into the adjuvant trial described above. Serum samples were obtained at study entry, within 2 mo of definitive surgery. At the time of serum acquisition, all patients were free of disease as judged by physical, laboratory, and radiological examination. Serum samples were aliquoted and stored at $-70^{\circ} \mathrm{C}$.

Protein A hemadsorption assay. The protein A hemadsorption assay was performed after the method described by Pfreundschuh et al. (16). Results were scored by an investigator blinded to the patient's clinical status. Indicator cells were prepared from staphylococcal protein A (Pharmacia Fine Chemicals, Upsala, Sweden) conjugated to human blood group $\mathrm{O} \mathrm{Rh}(+)$ red blood cells, with $0.01 \% \mathrm{CrCl}_{3}, \mathrm{pH} 5.0$, using equal volumes of packed red blood cells and protein $A$. All tests were done in duplicate. A positive cell was one in which $\geq 50 \%$ of the cell surface is

1. Abbreviations used in this paper: $\mathrm{AD \& U}$, acid dissociation and ultrafiltration; BCG, bacillus Calmette-Guerin; DTIC, 5-methyl-3,3-dimethyl1-triazeno)-imidazole-4-carboxamide; EBV, Epstein-Barr virus; ELISA, enzyme-linked immunosorbent assay; LDA, leukocyte-dependent antibody activity; MBEH, monobenzyl ether of hydroquinone. 
marked by indicator cells. The endpoint of the assay was the last dilution with $\geq 10 \%$ of melanoma cells $(+)$. Serological studies were scored positive if antibody titers were $\geq 1: 4$.

Acid dissociation and ultrafiltration $(A D \& U)$. The method described by Sjogren et al. (17) was used to dissociate immune complexes. To assure uniform processing of sera, an 8-chamber multichannel ultrafiltration apparatus (Amicon Corp., Danvers, MA) was used. Each chamber was fitted with an HP-30 membrane (Amicon Corp.) with a molecular weight exclusion of $100,000.2 \mathrm{ml}$ of serum were added to each chamber and $A D \& U$ was performed with glycine-saline buffer, $(0.1 \mathrm{M}, \mathrm{pH} 3.1)$ at $4^{\circ} \mathrm{C}$ under 20 psi $\mathrm{N}_{2}$. AD\&U was continued until 5-6 $\times$ the serum volume was reached (10-12 ml). Studies have shown that ultrafiltration of that volume allows maximal recovery of antibody (unpublished data). The serum was then washed with the same volume of phosphate-buffered saline to correct $\mathrm{pH}$.

\section{Cell lines}

Melanoma cell line Y-Mel 81:180, in passages 8-10, was used as the target for the serological studies reported here. Additional melanoma cell lines used in specificity testing included Y-Mel 82:550, 84:420, and 85:040. Epstein-Barr virus (EBV)-transformed lymphocyte cell line (Y-Lyc 81:180) obtained from the same patient as melanoma line YMel 81:180 was used in absorption testing. Preparation and maintenance of cell lines has been previously reported $(13,14)$.

\section{Immune complex assays}

Selected sera were tested for circulating immune complexes utilizing anti-Clq and anti-C3d enzyme-linked immunosorbent assay (ELISA) test systems (Ortho Diagnostic Test Systems, Raritan, NJ).

\section{Statistical methods}

The Wilcoxon two-sample rank sum test (18) was used to assess the association between antibody titer and relapse status. A multivariate analysis of antibody titer, stage of disease, and Breslow depth as prognostic variables for relapse was performed using step-wise logistic regression. The relationship of time to response with antibody titer was assessed using a Cox Regression Analysis.

\section{Results}

Patient characteristics. Patient characteristics are summarized in Table I and the distribution is similar to that of the 106 patients in the adjuvant trial from which this subgroup of patients was obtained. The sole criterion for patient selection was the availability of serum for study. All patients who had serum available were evaluated. No patients were lost to follow-up and there were no deaths in the disease-free group. Of the 15 patients who subsequently relapsed, 11 have died of progressive disease.

Of the 43 patients studied, 15 relapsed and 28 remained disease-free. At entry, there were 25 stage I patients and 18 stage II patients. In disease-free patients, median follow-up time was $4.8 \mathrm{yr}$ (range 2-7 yr). In the patients who relapsed, six were stage I and nine were stage II. Median time to relapse was $21 \pm 13$ mo overall. In stage I patients, median time to relapse was $24 \pm 14$ mo. In stage II patients, median time to relapse was $19 \pm 13 \mathrm{mo}$. Of the patients remaining disease-free, 19 were stage $I$ and 9 were stage II. Hypopigmentation was noted in six patients who relapsed (relapse patients) and nine disease-free patients. Breslow depth was $3.25 \pm 2.5 \mathrm{~mm}$ in relapse patients and $1.67 \pm 1.1 \mathrm{~mm}$ in disease-free patients. In both groups, there was a preponderance of male patients. This was a reflection of the male/female ratio found in the adjuvant study from which these patients were selected (15).

Serological studies. Native serum and serum subjected to $A D \& U$ were tested for antibody reactivity against allogeneic
Table I. Patient Characteristics

\begin{tabular}{lcc}
\hline & $\begin{array}{l}\text { Relapse } \\
(15)\end{array}$ & Disease-free (28) \\
\hline Male & 13 & 17 \\
Female & 2 & 11 \\
Age & $49 \pm 13$ & $44 \pm 12.4$ \\
Breslow depth $(\mathrm{mm})$ & $3.25 \pm 2.5$ & $1.67 \pm 1.1$ \\
Stage I & 6 & 19 \\
Stage II & 9 & 9 \\
Hypopigmentation & 6 & 9 \\
Relapse (mo) & $21 \pm 13$ & \\
Therapy & & \\
$\quad$ Null & 4 & 5 \\
$\quad$ DTIC/BCG & 5 & 12 \\
$\quad$ MBEH & 6 & 11 \\
Ulceration of primary & & \\
$\quad$ Present & 3 & 4 \\
$\quad$ Absent & 12 & 24 \\
Site of primary & & \\
$\quad$ Extremity & 5 & 12 \\
$\quad$ Truncal & 9 & 5 \\
$\quad$ Head and neck & 1 & \\
& &
\end{tabular}

cultured melanoma cell line Y-Mel 81:180. The overall distribution of antibody titers is shown in Fig. 1. The incidence and titer of antibody to melanoma were compared in relapse and disease-free patients. Comparisons were also made between native and AD\&U serum. Previously, we have reported that sera from six normal individuals showed no antibody reactivity to melanoma cells before or after AD\&U (13).

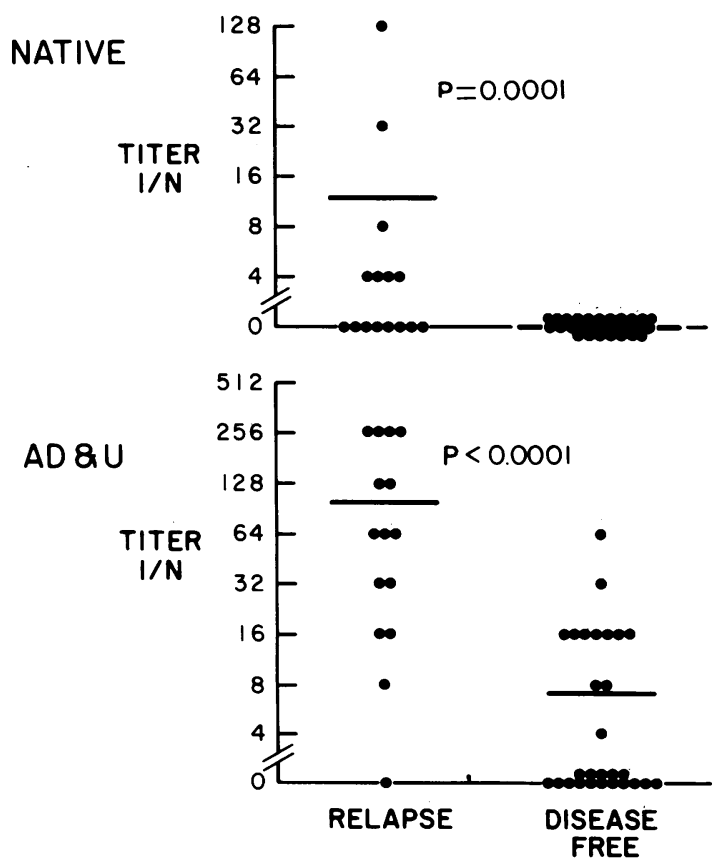

Figure 1. Overall distribution of antibody titers to melanoma Y-Mel $81: 180$ in patients who remained disease-free or subsequently relapsed in native and AD\&U serum. Horizontal bars indicate mean antibody titer. The $P$ values denote comparisons between antibody titers in relapse and disease-free groups. 
Table II. Specificity Analysis of Selected Sera*

\begin{tabular}{|c|c|c|c|c|c|c|}
\hline \multirow[b]{2}{*}{ Serum } & \multirow[b]{2}{*}{ Statusf } & \multicolumn{5}{|c|}{ Melanoma cell line } \\
\hline & & $81: 180$ & $81: 180$ \$ & $82: 550$ & $84: 420$ & $85: 040$ \\
\hline S776 & DF & + & 0 & + & 0 & + \\
\hline $\mathbf{S 9 3 9}$ & DF & + & + & + & + & + \\
\hline S75 & $\mathbf{R}$ & + & + & + & + & + \\
\hline S466 & $\mathbf{R}$ & + & + & + & + & + \\
\hline $\mathrm{S} 466^{\prime \prime}$ & & + & + & + & + & + \\
\hline S1349 & $\mathbf{R}$ & + & + & + & + & + \\
\hline S1349" & & + & + & + & + & + \\
\hline
\end{tabular}

* Direct testing was performed by protein A hemadsorption (see Methods). A positive cell was one in which $\geq 50 \%$ of the cell surface was marked by indicator cells. A positive test $(+)$ was one, at a serum dilution of $\geq 1: 4$, where $\geq 10 \%$ of the cells were $(+)$. $\ddagger R$, relapse; $D F$, disease-free. §Antibody reactivity against $Y$-Mel 81:180 following absorption with lymphocyte culture Y-Lyc 81:180. Absorption analysis was performed by mixing cells, at a ratio of $1: 1 \mathrm{vol} / \mathrm{vol}\left(1 \times 10^{8}\right)$ cells/ml minimum, with the serum to be tested, at a serum dilution two doublings below the endpoint of the titration for that serum found by direct testing. Antibody reactivity was considered to be absorbed if there was at least a twofold drop in antibody titer when compared to unabsorbed serum. "Serum subjected to acid dissociation and ultrafiltration (AD\&U; see Methods).

Native serum antibody reactivity to melanoma was found in 0:28 patients who remained disease-free and 7:15 patients (mean titer, 1:12) who subsequently relapsed. In sera subjected to AD\&U, 12/28 disease-free patients and $14: 15$ relapse patients demonstrated antibody reactivity. Mean antibody titer in serum subjected to $A D \& U$ was 1:7 in disease-free patients and 1:105 in relapse patients. The differences in antibody titers between disease-free and relapse patients were statistically significant in both native and AD\&U serum $(P=0.0001)$.

Specificity analysis. Sera from three relapse and two diseasefree patients were tested against three additional melanoma cell lines. Antibody reactivity was tested in both native and AD\&U sera when possible. Sera S779, S939, and S75 had no antibody reactivity in native sera. Antibody reactivity was noted against all three melanoma cell lines in four of five sera tested. Sera S779 detected two of three melanoma cell lines. These results are summarized in Table II. Antibody reactivity of these sera was also tested against melanoma Y-Mel 81:180 following absorption with EBV-transformed lymphocytes Y-Lyc 81:180 (obtained from the same patient as melanoma Y-Mel 81:180). Absorption with lymphocytes failed to reduce antibody reactivity against Y-Mel 81:180 in four of the five sera tested. The one exception was serum S776, which was obtained from a patient who has remained disease-free (Table II). No change in antibody reactivity was seen after absorption with fetal calf serum or BCG in all five sera.

Immune complex detection. Circulating immune complex levels were measured in six relapse patients and eight diseasefree patients. The same serum samples used to study antibody reactivity were used in immune complex measurement. In no instance were elevated levels of circulating immune complexes detected when measured by anti-Clq or anti-C3d ELISA assays. We have previously shown that elevated levels of circulating immune complexes were not detected by the Raji cells or ${ }^{125}$ I Clq binding assays in three autologous systems (14).

Statistical analysis. Statistical analysis revealed that the titer of antibody reactivity to melanoma bore a significant relationship to eventual relapse both in native $(P=0.0001)$ and AD\&U $(P<0.0001)$ sera. Serological results in groups stratified by stage of disease, Breslow depth, the presence of cutaneous hypopigmentation, sex, site of primary, ulceration, and subsequent therapy were evaluated. The most significant indicators of prognosis, in the clinical study to which these serological results pertain, were stage of disease, Breslow depth, and the presence of hypopigmentation (16) (Fig. 2). No prognostic significance was associated with the other variables shown in Table III. When grouped by prognostic variables, it was noted that recipients of depigmentation therapy with $\mathrm{MBEH}(n=17)$ and those with a primary lesion originating in an extremity $(n=14)$ failed to show a statistically significant association in native sera. This may be due to the small number of patients involved. However, after sera were subjected to AD\&U a statistically significant association was achieved. While AD\&U did not appear to change

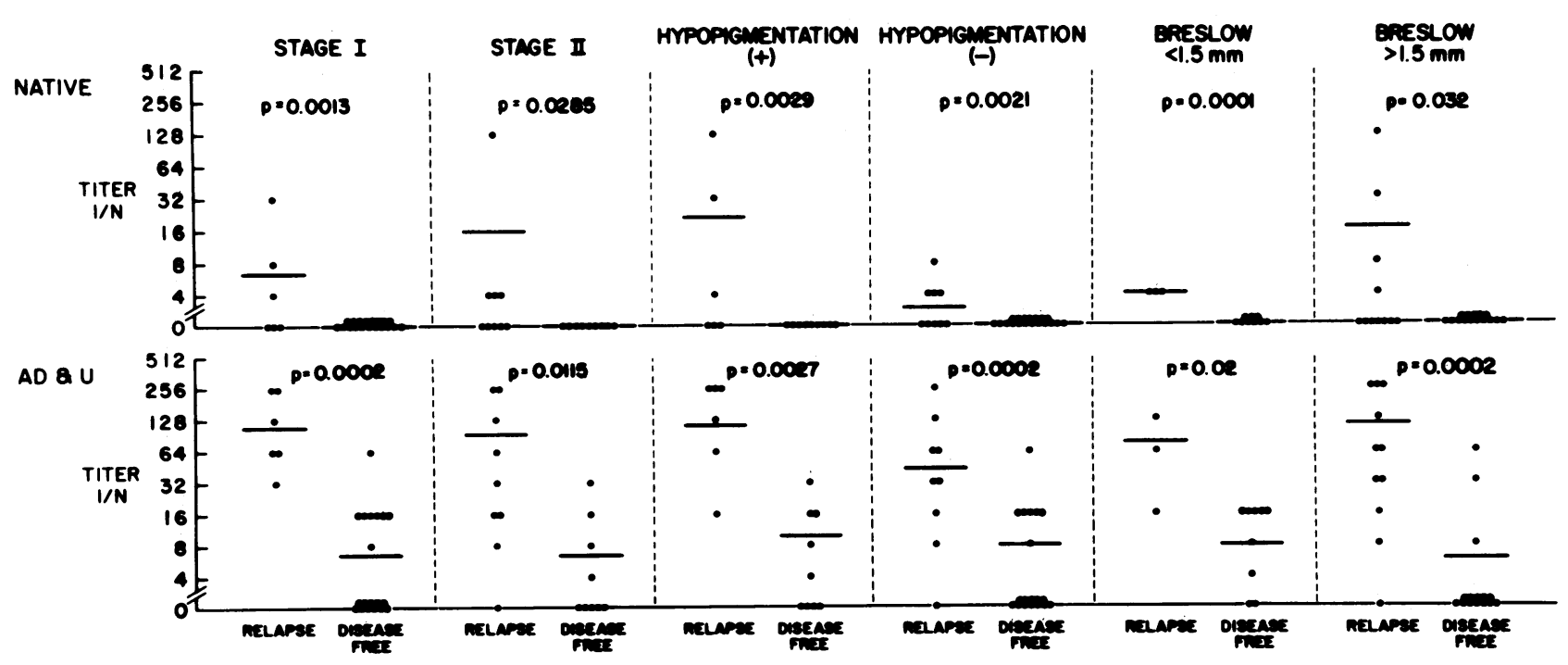

Figure 2. Distribution of antibody titers against melanoma Y-Mel 81:180 in native and AD\&U serum. Comparisons are made between selected prognostic groups. 
Table III. Statistical Analysis of Antibody Reactivity in Patients Who Relapse vs. Remain Disease-Free

\begin{tabular}{|c|c|c|}
\hline \multirow[b]{2}{*}{ Relapse vs. disease-free patients } & \multicolumn{2}{|l|}{$P$ value } \\
\hline & Native serum & AD\&U serum \\
\hline Overall & 0.0001 & $<0.0001$ \\
\hline Stage I patients & 0.0013 & 0.0002 \\
\hline Stage II patients & 0.0285 & 0.0115 \\
\hline \multicolumn{3}{|l|}{ Breslow depth } \\
\hline$\leq 1.5 \mathrm{~mm}$ & 0.0001 & 0.02 \\
\hline$>1.5 \mathrm{~mm}$ & 0.032 & 0.0002 \\
\hline \multicolumn{3}{|l|}{ Hypopigmentation } \\
\hline Present & 0.0029 & 0.0027 \\
\hline Absent & 0.0021 & 0.0013 \\
\hline \multicolumn{3}{|l|}{ Sex } \\
\hline Male & 0.0029 & 0.0002 \\
\hline Female & 0.0143 & 0.0279 \\
\hline \multicolumn{3}{|l|}{ Therapy } \\
\hline Null & 0.0935 & 0.0213 \\
\hline DTIC/BCG & 0.0006 & 0.0035 \\
\hline MBEH & 0.1757 & 0.0226 \\
\hline \multicolumn{3}{|l|}{ Ulceration of primary } \\
\hline Present & 0.248 & 0.0416 \\
\hline Absent & 0.0002 & 0.0002 \\
\hline \multicolumn{3}{|l|}{ Site of primary } \\
\hline Extremity & 0.1792 & 0.0146 \\
\hline Truncal/Head and neck & 0.0004 & 0.0002 \\
\hline
\end{tabular}

the overall predictive value of these serological studies, it provided a greater discrimination between some subsets.

Melanoma antibody titers were evaluated in relationship to relapse, in a multivariate logistic regression analysis, accounting for other prognostic variables. Antibody titer was found to be a significant predictor of relapse independent of stage of disease and Breslow depth. In a Cox Regression Analysis, the association for antibody titer in relationship to time to relapse was significant at $\alpha=0.016$ level for native sera and $\alpha=0.08$ level for AD\&U sera.

\section{Discussion}

This study was carried out to determine whether antibody reactivity to a melanoma cell line bearing a common melanoma cell surface antigen (13) might demonstrate any relationship to the natural history of the disease in patients entered into a prospective adjuvant trial. This paper is an extension of previous work in which we noted that autologous antibody reactivity in patients with metastatic melanoma, followed serially, could be correlated with clinical course (14). Our results demonstrate that the presence and titer of antibody reactivity against cultured allogeneic melanoma cells is associated with eventual tumor recurrence. The significance of this factor is surprising $(P=0.0001)$, and its association with relapse is the opposite from that which has been reported elsewhere $(11,12)$.

A number of prognostic factors have been described in patients with stage I and II melanoma. They include: the presence of lymph node involvement, tumor thickness, lymphocytic infiltration of the primary, ulceration, site of primary, age, sex, and others (19-23). This study suggests that the presence and titer of antibody reactive against melanoma is a new prognostic factor in patients who present with surgically curable melanoma.

When the patients were further grouped by stage of disease, Breslow depth, and the presence or absence of hypopigmentation, antibody reactivity was still found to be significantly associated with relapse (Table III, Fig. 2). In addition, it was found that the level of antibody titer was associated with the time to relapse. Finally, a multivariate logistic regression analysis found that antibody titer was significantly associated with relapse in the presence of stage of disease and Breslow depth.

Other investigators have examined the prognostic role of antibody and tumor-associated antigens in melanoma $(11,12)$. Jones et al. (12) found that elevated levels of IgM antibody directed against a melanoma-associated oncofetal antigen were positively correlated with an increased disease-free interval. Werkmeister et al. (11) noted that patients whose melanoma cells were reactive with melanoma-associated antiserum $\mathrm{CHI}$ had a longer disease-free period.

In native serum, antibody reactivity against melanoma was found in only 7 of 43 patients studied (16\%), all of whom subsequently relapsed. These results (Fig. 1) demonstrate the prognostic association of antibody directed against melanoma and disease recurrence. However, the low incidence and titer of these antibodies hamper their further use. Our previous work has shown that treatment of serum by AD\&U augmented reactivity of autologous antibody to melanoma in 9 of 10 cases studied $(13,14)$. The results reported here illustrate the significance of circulating immune complexes as a reservoir of tumor-reactive antibody and again demonstrate that antibody reactivity in serum can be augmented when subjected to AD\&U. Following AD\&U, the serum of 26 patients $(60 \%)$ demonstrated antibody reactivity to melanoma. The overall association with relapse in the serological studies of serum subjected to AD\&U was not markedly altered from those obtained in native serum. However, when the results were stratified by various prognostic factors, serum results obtained following AD\&U appeared to allow a greater discrimination between some subgroups (Table III).

Specificity testing of sera obtained from three relapse and two disease-free patients demonstrated antibody reactivity against three melanoma cell lines in addition to Y-Mel 81:180. These results suggest that the antigen detected is broadly represented in melanoma. In order to determine if the antibody was detecting a histocompatibility antigen, absorption with EBVtransformed lymphocytes (Y-Lyc 81:180), obtained from the same patient as melanoma cell line Y-Mel 81:180, was performed. Antibody reactivity against melanoma Y-Mel 81:180 was not removed following absorption in all three relapse patients and one patient who has remained disease-free. The one exception to this was in the sera of a disease-free patient (S776), suggesting that in that instance the antibody detected was directed against a histocompatibility antigen. The fact that antibody reactivity was removed by EBV-transformed lymphocytes in one patient who has remained disease-free adds further weight to the prognostic power of the serologic studies reported here.

Studies evaluating the role of immune complexes in malignancy have found the presence of elevated levels of circulating immune complexes to be positively correlated with stage of disease, tumor burden, and a worse prognosis. Carpenter et al. (24) reported a strong correlation between immune complex levels and patients with acute myeloid leukemia. Patients with elevated levels of circulating immune complexes were found to have a poorer prognosis. Rossen et al. (25) found that, in 53 patients 
with advanced melanoma, the presence of Clq-binding immune complexes was correlated with a shorter survival than those without elevated levels of circulating immune complexes. More recently, Gupta and Morton (26) reported that the presence of tumor-associated antigen or immune complexes in patients with stage II melanoma was correlated with a higher rate of recurrence.

Our failure to detect elevated levels of circulating immune complexes in the sera of the patients studied here, using two assays, does not rule out the presence of tumor-associated immune complexes in our patients. Ruell et al. (27) reported that, in patients with melanoma, although the incidence of immune complexes rises with stage of disease, the low prevalence of detectable complexes limited their diagnostic utility. Immune complex levels often dropped prior to clinical relapse, suggesting that antigen excess was a frequent cause for the failure to detect immune complexes. No assay currently available reliably detects small noncomplement binding immune complexes, as might be found in patients with malignancy and large quantities of circulating antigen (28).

What role the antibodies we have detected may play in the pathophysiology of melanoma remains to be determined. It may be that the antibody is reacting to subclinical deposits of tumor cells. If this is the case, serological studies of antibody reactivity may provide a highly sensitive indicator of residual disease. Alternatively, the antibody may be involved in modifying the host's humoral and cellular immune responses. Murray et al. (29) found that the serum of patients with disseminated melanoma contained a factor which blocked leukocyte-dependent antibody activity (LDA): Serum treated by AD\&U was able to restore LDA against allogeneic melanoma cells. LDA was blocked by whole serum, the filtrate removed by AD\&U, and a combination of filtrate and retentate. They postulated that immune complexes and tumor-associated antigen may be involved in the immunomodulation of the host's response. Subsequent studies have reported that the presence of LDA could be correlated with a better prognosis (30).

The immunoregulatory role of antibody to melanoma is unknown in man. In experimental animals, the capacity of antibody to regulate anti-tumor effects has been studied for nearly two generations in the setting of "immune enhancement" $(28,31-$ 35). It is unknown whether the antibody reactivity against melanoma cells reported here is involved in the regulation of the host's immune response. Our findings suggest that tumor-reactive antibody, the antigen against which they may be directed, or the immune complexes that are formed, may provide an explanation of the natural history of melanoma. The tools for the dissection of the various components of the cellular and humoral responses are now available. The prognostic association documented here underscores the importance of further work to determine the nature of the tumor immune response and biochemical nature of the antigens against which it is directed.

\section{Acknowledgments}

The authors would like to thank Dr. Barry Solomon, of the Advanced Research Group of W. R. Grace (Danvers, MA) for technical advice and material. We would also like to thank Ms. Judy Fine for data management.

\section{References}

1. Old, L. J. 1981. Cancer immunology: the search for specificity. G. H. A. Clowes Memorial Lecture. Cancer Res. 41:361-374.
2. Carey, I. E., K. O. Lloyd, T. Takahashi, L. R. Travassos, and L. J. Old. 1979. Cell-surface antigen of human malignant melanoma: solubilization and partial characterization. Proc. Natl. Acad. Sci. USA. 76:2898-2902.

3. Galloway, D. R., R. P. McCabe, M. A. Pellegrino, S. Ferrone, and R. A. Reisfeld. 1981. Tumor-associated antigens in spent medium of human melanoma cells: immunochemical characterization with xenoantisera. J. Immunol. 126:62-66.

4. Heaney-Kieras, J., and J.-C. Bystryn. 1982. Identification and purification of a $75 \mathrm{~K}$ dalton cell-surface human melanoma associated antigen. Cancer Res. 42:2310-2316.

5. Koprowski, H., A. Steplewski, D. Herlyn, and M. Herlyn. 1978. Study of antibodies against human melanoma produced by somatic cell hybrids. Proc. Natl. Acad. Sci. USA. 75:3405-3409.

6. Dippold, W. G., K. O. Lloyd, L. T. C. Li, H. Ikeda, H. F. Oettgen, and L. J. Old. 1980. Cell surface antigens of human malignant melanoma: definition of six antigenic systemic with mouse monoclonal antibodies. Proc. Natl. Acad. Sci. USA. 77:2183-2187.

7. Carey, H., T. Takahashi, L. Resnick, and H. F. Oettgen. 1976. Cell surface antigens of human malignant melanoma. I. Mixed hemadsorption assays for humoral immunity to cultured autologous melanoma cells. Proc. Natl. Acad. Sci. USA. 73:3278-3282.

8. Carey, T. E., K. O. Lloyd, A. N. Houghton, H. F. Oettgen, and L. J. Old. 1979. AU cell surface antigens of human malignant melanoma: solubilization and partial characterization. Proc. Natl. Acad. Sci. USA. 76:2898-2902.

9. Shiku, H., T. Takahashi, H. F. Oettgen, and L. J. Old. 1977. Cell surface antigens of human malignant melanoma II. Serological typing with immune adherence assays and definition of two new surface antigens. J. Exp. Med. 144:873-881.

10. Shiku, H., T. Takahashi, L. Resnick, H. F. Oettgen, and L. J. Old. 1977. Cell surface antigens of human malignant melanoma III. Recognition of auto-antibodies with unusual characteristics. J. Exp. Med. 145:784-789.

11. Werkmeister, J., A. Edwards, W. McCarthy, and P. Hersey. 1980. Prognostic significance of expression of antigens on melanoma cells. Cancer Immunol. Immunother. 9:233-240.

12. Jones, P. C., L. I. Sze, P. Y. Liu, D. L. Morton, and R. F. Irie. 1981. Prolonged survival for melanoma patients with elevated IgM antibody to oncofetal antigen. J. Natl. Cancer Inst. 66:249-254.

13. Kirkwood, J. M., and D. R. Vlock. 1984. Augmentation of autologous antibody to human melanoma following acid dissociation and ultrafiltration of serum. Cancer Res. 44:4177-4182.

14. Vlock, D. R., and J. M. Kirkwood. 1985. Serial studies of autologous antibody reactivity to melanoma: Relationship to circulating immune complexes and clinical course. J. Clin. Invest. 876:849-854.

15. Kirkwood, J. M., J. Nordlund, A. Lerner, M. Ernstoff, R. DerSimonian, J. Fine, M. Melia, B. Forget, and D. R. Vlock. 1985. Favorable prognosis of melanoma associated with hypopigmentation in a randomized trial comparing DTIC-BCG vs Monobenzyl ether of hydroquinone vs null treatment. Proc. Am. Soc. Clin. Oncol. 4:C-581.

16. Pfreundschuh, W., H. Shiku, T. Takahashi, R. Ueda, J. Ransohoff, H. F. Oettgen, and L. J. Old. 1978. Serological analysis of cell surface antigens of malignant human brain tumors. Proc. Natl. Acad. Sci. USA. 75:5122-5126.

17. Sjogren, H. O., I. Hellstrom, S. C. Bansal, and K. E. Hellstrom. 1971. Suggestive evidence that the "blocking antibodies" of tumor-bearing individuals may be antigen-antibody complexes. Proc. Natl. Acad. Sci. USA. 68:1372-1375.

18. Moses, L. E., J. Emerson, and H. Husseini. 1984. Analysis of data from ordered categories. $N$. Engl. J. Med. 311:442-448.

19. Balch, C. M., S-j. Soong, H. M. Shaw, and G. W. Milton. 1984. An analysis of prognostic factors in $\mathbf{4 0 0 0}$ patients with cutaneous melanoma. In Cutaneous Melanoma. Clinical Management and Treatment Results Worldwide. C. M. Balch and G. W. Milton, editors. J. B. Lippincott Co., Philadelphia, PA. 321-352.

20. Balch, C. M., S-j. Soong, G. W. Milton, H. M. Shaw, V. J. McGovern, T. M. Murad, W. H. McCarthy, and W. A. Maddox. 1982. 
A comparison of prognostic factors and surgical results in 1,786 patients with localized (stage I) melanoma treated in Alabama, USA, and New South Wales, Australia. Ann. Surg. 196:677-685.

21. Day, C. L. Jr., R. A. Lew, M. C. Mihm Jr., M. N. Harris, A. W. Kopf, A. J. Sober, and T. B. Fitzpatrick. 1981. The natural break points for primary-tumor thickness in clinical stage I melanoma. N. Engl. J. Med. 305:1155-1160.

22. Breslow, A. 1970. Thickness, cross-sectional areas and depth of invasion in the prognosis of cutaneous melanoma. Ann. Surg. 172:902910.

23. Johnson, O. K. Jr., L. J. Emrich, C. P. Karakousis, U. Rao, and W. R. Greco. 1985. Comparison of prognostic factors for survival and recurrence in malignant melanoma of the skin, clinical stage I. Cancer. (Phila.). 1985; 55:1107-1117.

24. Carpenter, N. A., D. M. Fiere, D. Schull, G. T. Langeand, and P. Lambert. 1982. Circulating immune complexes and the prognosis of acute myeloid leukemia. N. Engl. J. Med. 307:1174-1180.

25. Rossen, R. D., M. M. Crane, A. C. Morgan, E. H. Giannini, B. C. Giovanella, J. S. Stehlin, J. J. Twomey, and E. M. Hersh. 1983. Circulating immune complexes and tumor cell cytotoxins as prognostic indicators in malignant melanoma: a prospective study of 53 patients. Cancer Res. 43:422-429.

26. Gupta, R. K., and D. L. Morton. 1985. Detection of tumorassociated antigen, antibody and immune complexes in sera from melanoma patients. Proc. Am. Assoc. Cancer Res. 26:1120.
27. Ruell, P., E. Murray, W. H. McCarthy, and P. Hersey. 1982. Evaluation of assays to detect immune complexes as a diagnostic aid in patients with melanoma. Oncodev. Biol. Med. 3:1-12.

28. Theofilopoulos, A. N., B. S. Andrews, M. M. Urist, D. L. Morton, and F. J. Dixon. 1977. The nature of immune complexes in human cancer sera. J. Immunol. 119:657-663.

29. Murray, E., W. H. McCarthy, and P. Hersey. 1977. Blocking factors against leucocyte-dependent melanoma antibody in the sera of melanoma patients. Br. J. Cancer. 36:7-17.

30. Hersey, P., A. Edwards, E. Murray, W. H. McCarthy, and G. W. Milton. 1983. Prognostic significance of leucocyte-dependent antibody activity in melanoma patients. $J$. Natl. Cancer Inst. 71:45-53.

31. Kaliss, N. 1958. Immunological enhancement of tumor homografts in mice: a review. Cancer Res. 18:992-1003.

32. Roth, J. A. 1983. Tumor induced immunosuppression. Surg. Gynecol. Obstet. 156:233-240.

33. Lewis, M. G., T. M. Phillips, and G. Rowden. 1978. Beneficial and detrimental effects of humoral immunity in malignancy. Pathiobiol. Annu. 8:217-239.

34. Oberbarnscheidt, J., and E. Kolsch. 1978. Direct blockade of antigen-reactive B lymphocytes by immune complexes. An "off" signal for precursors of IgM-producing cells provided by the linkage of antigenand Fc-receptors. Immunology. 35:151-157.

35. Baldwin, R. W., M. R. Price, and R. A. Robins. 1973. Inhibition of hepatoma-immune lymph node cell cytotoxicity by tumor-bearer serum and solubilized hepatoma antigen. Int. J. Cancer. 11:527-535. 